NOTAS

\title{
EL RESENTIMIENTO
}

Alberto Buela*

RESUMEN: En esta nota se contraponen los conceptos de resentimiento según Nietzsche y Scheler; se abre la pregunta sobre la posibilidad de la superación del mismo; finalmente, se vincula con la esfera política.

PALABRAS ClAVE: resentimiento, cristianismo, perdón, Nietzsche, Scheler.
ABSTRACT: In this article, a contrast of Nietzsche and Scheler's concepts of resentment is presented; a discussion unfolds regarding the possibility of overcoming it, and finally, its connection to politics will be explored.

KEYWORDS: resentment, christianism, forgiveness,
RECEPCIÓN: 31 de julio del 2008.

ACEPATACIÓN: 14 de septiembre del 2008.
* Filósofo y metapolítico. 


\section{EL RESENTIMIENTO}

$\mathrm{E}_{\text {n estos días se habla mucho desde }}$ los grandes medios de comunicación acerca del tema del resentimiento en el accionar político. Y como a nosotros nos han preguntado ya varias veces sobre el tema, intentaremos, en forma breve y clara, fijar algunas notas sobre el concepto mencionado.

El resentimiento es un fenómeno complejo, basado en la conciencia de la propia incapacidad y flaqueza, principalmente cuando esa incapacidad no permite llevar a cabo la venganza deseada.

Su importancia en la génesis de la moral es que puede dar lugar a una inversión de la jerarquía de valores, juzgando como superiores los valores que se pueden realizar y como despreciables los valores que son inac- cesibles para el hombre resentido. Existe una conciencia de impotencia frente a los valores verdaderos.

El resentimiento es una autointoxicación psíquica que surge al reprimir sistemáticamente los afectos y las descargas emocionales normales. Revela la conciencia de la propia impotencia pues lleva a refrenar ese impulso espontáneo de venganza que se va acumulando y retrasando, así, el contraataque.

El resentimiento acumulado acaba por deshumanizar al contrincante, abriendo así la puerta al exterminio. Como dijo un asesino de las FARC: "Yo no he matado a una persona, he matado a un empresario".

El resentimiento se manifiesta mediante el sentimiento de rencor que 
podemos definir como "odio retenido", de ahí que antiguamente se llamaba "amargos" a los resentidos porque retienen la ira por largo tiempo. ${ }^{1}$

Se debe a Robespierre, el gran jacobino de la Revolución francesa, el mérito de haber sintetizado en una frase la psicología de aquella Revolución como del resentimiento: "Sentí, desde muy temprano, la penosa esclavitud de tener que agradecer". El resentido padece una ceguera moral respecto de la gratuidad, la donación y el agradecimiento.

El resentimiento fue estudiado en profundidad por dos autores alemanes contrapuestos en este punto: Federico Nietzsche, en La Genealogía de la Moral, y Max Scheler, en El Resentimiento en la Moral.

Es sabido que la forma del razonamiento de Nietzsche en todas sus obras es por medio de una refinada psicología que explica las cosas ad inferiori, por lo bajo. "Esta interpretación sofística y psicologizante consiste en interpretar la genealogía del ideal desde su contrario", ${ }^{2}$ ha podido afirmar su más eximio y leal estudioso. Así va a sostener que la santidad tiene su

${ }^{1}$ Tomás de Aquino, S.T., I-IIae, q. 46, "De las especies de iras".

${ }^{2}$ Eugen Fink, La filosofia de Nietzsche, 1966, Madrid, Alianza, p. 64. Nietzsche ve a los judíos como el pueblo sacerdotal y genio del rencor y, en este aspecto hay coincidencia con Scheler, quien afirma que el pueblo judío es el más antiguo usuario del resentimiento (cfr. op. cit., p. 204). origen en la perversión, la verdad en el instinto de engaño, el derecho en la voluntad de aprovechamiento del otro. Piensa que la caridad, la castidad, la humildad y la paciencia son vistas como valores sólo por los débiles, por la moral de esclavos de los cristianos, que son aquellos que no tienen fuerza para superar la opresión y las situaciones de injusticia.

Nietzsche, como pensador anticristiano por antonomasia, va a afirmar en forma tajante: "Desde su impotencia, crece en ellos el odio hasta convertirse en algo gigantesco y siniestro, en lo más espiritual y lo más venenoso. Los más grandes odiadores de la historia mundial siempre han sido los sacerdotes". ${ }^{3}$

Max Scheler va a responder que este razonamiento es falso en lo que atañe a la moral cristiana, pues el perdón cristiano no es un poder no vengarse por debilidad personal, sino el privarse libremente de la satisfacción de la venganza, que es algo muy distinto.

El cristiano genuino tiene conciencia espontánea de su propio valor, lo cual le da seguridad y le permite aceptar el valor de los demás, incluso cuando son superiores a él. El resentido, por el contrario, en lugar de reconocer los valores superiores y resignarse,

${ }^{3}$ Nietzsche, La Genealogía de la moral, 2003, Madrid, Tecnos, p. 74. 
NOTAS

los rebaja, negando la bondad de aquello mismo que envidia.

El motor de la moral cristiana no es el desear lo que no se tiene sino que consiste en el darse y donarse, por parte de quien tiene, y se siente lleno de valor y felicidad. Es un movimiento que brota de la más íntima seguridad en la plenitud de su propio ser.

Nietzsche, para Scheler, confundió y asimiló el cristianismo a la moral burguesa de su tiempo, propia de los pastores luteranos, como fue su padre, ignorando la naturaleza del cristianismo católico. La moral burguesa, afirma Scheler, ha transformado el amor cristiano en pura filantropía sentimental, que lo reduce a la simpatía, la emoción o a un sentimiento de lástima. Scheler defiende con fuerza la gran diferencia que existe entre la misericordia cristiana auténtica y la moderna lástima sensiblera. A la radical desconfianza en el otro, propia del mundo burgués, opone la solidaridad moral característica de la comunión de los santos.

A la multiplicación infinita de medios en el mundo burgués, y una clara confusión en los fines, opone el mundo católico de la Edad Media que, con un mínimo de medios, se sabía gozar en ellos mismos. Incluso el ascetismo de aquella época provocaba una mayor capacidad de goce con el mínimo de cosas agradables: una gota de lluvia sobre una hoja.
El cristiano burgués y luterano contra el que reacciona Nietzsche no es el mejor ejemplo de lo que sea el cristianismo. Queda finalmente por responder si puede el hombre salir o liberarse del resentimiento.

Nosotros entendemos que del resentimiento se puede salir de cuatro formas o maneras: $a$ ) la primera y más expeditiva es la venganza de la ofensa, que produce la liberación del odio retenido o rencor; $b$ ) la segunda posibilidad es el perdón, que es sacrificar libremente el valor de la satisfacción que produce la venganza, pero al mismo tiempo sólo se perdona auténticamente cuando uno todavía se siente lastimado. El perdón no es un favor, una gauchada, que le hacemos a quien nos injurió, sino que es un acto por el cual quedamos libres del mal que nos hicieron; c) la tercera actitud es por medio del olvido, lo que implica el paso del tiempo; y, por último, d) tenemos el duelo, interpretando de otra forma la ofensa, reubicándola en el recuerdo.

Vemos, pues, que lo determinante en el surgimiento del resentimiento así como su solución o superación no radica tanto en la ofensa sino en la respuesta personal a la misma. De ahí que una misma agresión u ofensa hecha por igual a varias personas en unos cause un sentimiento pasajero de dolor y en otros despierte un resentimiento perdurable. 


\section{El resentimiento en política}

El resentido con poder, cuando actúa en la esfera política, tiñe su accionar con sus propios prejuicios y así divide el mundo entre incluidos y excluidos, según coincidan con su visión de las cosas, el mundo y sus problemas. El resentido con poder, al no poder perdonar, queda anclado en un pasado que no puede olvidar. Así, para él el pasado es un pasado que no termina nunca de pasar. No puede olvidar. En realidad el resentimiento manifiesta mejor su naturaleza en el ámbito social y político que en el campo individual. Quien ha mostrado esto con mayor hondura ha sido el médico y pensador español Gregorio Marañón(1887-1960) en su libro Tiberio: Historia de un resentimiento. El emperador de Roma en la época de Cristo es el modelo por excelencia del hombre público resentido. Un hombre débil y cobarde que cuando alcanza el poder político adquiere una "fortaleza advenediza" que le permite aplicar tardíamente la venganza sobre los más pequeños aspectos de su vida personal pasada. En ese momento, en el de la ejecución de las pequeñas venganzas personales, es incapaz de agradecer la mínima ayuda de sus más allegados colaboradores. El egocentrismo llega a su máxima expresión: "el triunfo, lejos de curar al resentido, lo empeora, y es una de las razones de la violencia vengativa que el resentido ejerce cuando alcanza el poder. ${ }^{4}$

Tiberio, y como él los tantos Tiberios que hubo en el mundo y que seguramente habrá, son ejemplo concreto y viviente del sentido etimológico del rencor, tanto en griego

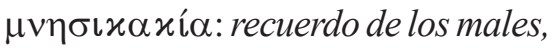
como en latín, rancor, que equivale a odio retenido.

Para los romanos, el término rencor provenía, como dijimos, de rancor (queja u odio) y de la misma raíz rancproviene rancio: sabor u olor fuerte de algo que pasado el tiempo se echa a perder. Y como dato curioso agreguemos que de la misma raíz proviene el sustantivo rengo, sujeto a quien el saber popular atribuye ser portador de "mala suerte". Y es sabido que la mala suerte en la vida está, junto con las ofensas no respondidas, en el origen del resentimiento.

En definitiva, como en política lo que aparenta es, pues sólo existe políticamente aquello que aparece, porque la política es siempre política pública, para el político resentido lo que importa no es el daño sufrido sino lo que queda del daño. "A él no le interesa la herida, lo que le importa es la cicatriz", afirmó acertadamente Jacques Lacan. Esta brillante observación se puede aplicar a cuanto político u

${ }^{4}$ Gregorio Marañón, Tiberio. Historia de un resentimiento, 1939, Buenos Aires, Espasa-Calpe, p. 173. 
NOTAS

hombre con poder resentido hay en el mundo.

La pregunta que surge naturalmente es si el resentimiento político es incurable, como sostenía Marañón, o puede remediarse. En este sentido, es interesante rescatar la distinción que realiza un psicoanalista, Luis Kancyper, quien propone, para poder superar el resentimiento político, pasar de la "memoria del rencor" a la "memoria del dolor": "El sujeto rencoroso (resentido y remordido) es un mnemorista implacable. Se halla poseído por reminiscencias vindicativas. No puede perdonar ni perdonarse. No puede olvidar", ${ }_{5}^{5}$ mientras que la memoria del dolor "admite al pasado como experiencia y no como lastre; no exige la renuncia al dolor de lo ocurrido y lo sabido", ${ }^{6}$ con ello se logra la elaboración de un duelo normal y prevenir la repetición de lo malo. Y termina, como buen argentino, con unas estrofas del Martín Fierro:

Es la memoria un gran don, Calidá muy meritoria

$\mathrm{Y}$ aquellos que en esta historia Sospechen que les doy palo Sepan que olvidar lo malo También es tener memoria.
Estos versos, telúricos y gauchos, encierran un saber sapiencial, esto es, una sabiduría práctica que viene desde el fondo de la historia y digna de tener en cuenta, pues abrevian el remedio a esa enfermedad que es el resentimiento, como enseñó ese gran monje asceta que fue Juan Clímaco (525-606): "el olvidar las ofensas es indicio de sincera penitencia". Pero este es el comienzo o primer momento en la derrota del resentimiento político; el segundo y definitivo paso de su superación se produce cuando ayudamos a quien nos ofendió, "acumulando así carbones encendidos sobre su cabeza" al decir de San Pablo. ${ }^{7}$

Definitivamente, sólo el devolver el bien por mal nos permite superar el mal; de lo contrario, volem nolem, quedamos atrapados por éste. Llegamos así, sin quererlo, al fundamento de la comunidad política que es la amistad recíproca, honestas amicitia o $\alpha \dot{v} \tau \iota \varphi \iota \lambda \hat{\imath} \alpha$ que no se agota en el placer o la utilidad como los otros tipos de amistades, sino que se mueve en busca de un mismo placer y una finalidad útil a las partes.

${ }^{5}$ Luis Kancyper, La compasión desterrada, en Internet, 2008.

${ }^{6}$ Ibidem.

${ }^{7}$ Rom. 12, 20-21. 